\title{
Diagnosis, Modeling and Prognosis of Learning System using Fuzzy Logic and Intelligent Decision Vectors
}

\author{
Lovi Raj Gupta \\ Senior Dean, \\ Lovely Professional University, \\ Phagwara, Punjab, India
}

\author{
Avneet Kaur Dhawan \\ Lecturer, \\ Lovely Professional University, \\ Phagwara, Punjab, India
}

\begin{abstract}
In this paper fuzzy Expert Systems are used that are based on fuzzy logic and intelligent decision vectors to handle the quantitative as well as qualitative aspects in measuring the performance of an Educational Institution. The Academic performance of any institution is governed by various parameters that need to be studied in linguistic form. In the present work, a structured mathematical model is developed for individualistic and interdependent effects of these factors. Through fuzzification, we have converted the crisp values into linguistic variables like very good, good, medium, low, high, very high. The two prime functions, each for in-class and outclass activities are formulated then a control function for weaving the parameters within the function is crafted. A regulating function to encompass the dependencies of two prime functions is framed. A decision vector to engross both the prime and control function is originated to suggest the modifications on the present practices for enhancement of academia and overall performance of the institute.
\end{abstract}

\section{General Terms}

Expert System, Fuzzy Logic, Linguistic Variables, Defuzzification.

\section{Keywords}

Learning System, Parametric Prognosis, Modeling, Intelligent Decision vectors, Higher Education.

\section{INTRODUCTION}

An Expert System is computer-based systems that uses knowledge and facts, working memory and apply an appropriate reasoning technique (inference) to solve problems in a given field (domain) that normally require the services of human experts. An expert system can be designed based on a set of rules to determine what action to set off when a certain situation is encountered. [1] If we talk about a human expert moving to an organization and checking out the institutional performance requisites, it would be a very costly affair as human experts of any field are always few in numbers, expensive to consult and they have short time due to much of the work they are supposed to do. So we feel that there is an urgent need of storing the expert's knowledge in the computer in such a way that have a great extent of knowledge of problem domain. As human beings are prone to errors, have feelings and emotions and are sometimes partial, the expert system will be solving problems of the users perfectly and sparing experts for others works. In this paper we propose the university diagnostic system through AI technology at higher education that can be used as a base for the performance measurement in an institute. The proposed Fuzzy Expert
System will be considering various inside as well as outside class parameters such as pedagogical initiatives, research \& publication, presentation, discipline, tests taken, assignments given, library, forums, distance learning courses, training and placement etc that have deep influence on the educational performance of an institute on the whole. The proposed Learning Diagnostic System can be used to measure the performance of an educational in situation whenever and wherever required and is flexible enough that it could be enhanced with time.

\section{REVIEW OF LITERATURE}

From last few decades, academicians, engineers, scientists and researchers began to recognize the importance of expert system and its related concepts like fuzzification, defuzzification, natural language processing, role of logic etc in decision making and knowledge management. History speaks that expert systems have been developed in varying fields like agriculture, chemistry, computer science, engineering, geology, medicine, space technology etc. [14]; and widely applied to various studies and issues, including performance assessment $[3 ; 26 ; 27]$, commercial loan underwriting [19], logistics strategy design [11], farm productivity [25], mergers and acquisitions [28], defence budget planning [29], earthquake design [6], system dynamics [32], conveyor equipment selection [15], customer service management [9] and knowledge inertia [20]. For example, in [13] used the development and implementation of an educational tool based on knowledge based technology employing an expert system shell- a knowledge base system for postgraduate engineering courses. In [17] extract project WBS from the obtained mind map of brainstorming project team by artificial intelligence (AI) tools which is Prolog programming language. In [5] used expert system technology for providing developmental feedback to individuals from different ethnic minority groups. Melek and Sadeghian, [22] developed a theoretic framework for intelligent expert systems in medical encounter evaluation. Shen et al., [31] constructed an intelligent assessment system model and compared with the current assessment in education, this new intelligent assessment system expands the range of object for evaluation and takes some AI technologies to give more heuristic and intelligent assessments. According to L.A. Zadeh $[33,34]$ variables words or sentences as their values is called linguistics variables and the variables that represents the gradual transition from high to low, true to false are called fuzzy variables and a set containing these variables is the fuzzy set. Fuzzy logic can be incorporated into expert system to enhance the performance and reliability of expert system in decision making. Fuzzy logic principals with expert system 
form a fuzzy expert system which is able to implement human knowledge \& expertise with imprecise, ambiguous and uncertain data. Recently, many researchers worked on the applications of fuzzy logic in education \& assessments. Chiang and Lin [10] presented a method for applying the fuzzy set theory to teaching assessment. Bai and Chen [4] presented a new method for evaluating students learning achievement using fuzzy membership functions and fuzzy rules. Chang and Sun [8] presented a method for fuzzy assessment of learning performance of junior high school students. Chen and Lee [7] presented two methods for student's performance evaluation using fuzzy sets. Ma and Zhou [21] presented a fuzzy set approach to the assessment of student-cantered learning. In [30] presented a method for applying the fuzzy set theory and the item response theory to evaluate the learning performance of students. The literature reveals that there is a vast potential of expert system and fuzzy logic in education and performance assessment.

\section{RESEARCH PROBLEM}

In many of the educational institutions, the same set of courses with static syllabi is taught to the students every year. The teaching is treated as a routine activity and some particular books are used for years. Very limited demonstrations or pedagogical tools are used as they do not have the proper direction to succeed in the global market. Due to this the students lag behind in updating their knowledge and applying the same in real time scenario. Majority of educational institutions have started faculty development programs in order to train future faculties and they do get support as well but unfortunately there is no roadmap or a strategic plan that could help an educational institution to diagnose its performance, work on the parameters and rank higher. To put the resources as well as human intelligence on track, it's very essential to evaluate their performance both internally and externally, may be in quarterly, in semester or annually, depending upon the resources universities posses. Although, the Higher Education Commission (HEC) has done a lot regarding quality assurance by establishing an idea of the Quality Enhancement Cells (QEC) in universities; but is rarely followed by educational institutions due to time consuming manual process and lack of available funds. Even those who follow they consider only a few parameters and do not have the standard procedures to improve the things for the betterment.

In this research, an intelligent expert system is adopted using fuzzy logic principals for university evaluation process. The set of parameters from literature that have vital influence on teachers evaluation by any means in higher education are extracted then divided into 9 major groups as shown in TableI:

Table 1. Groups Of Attributes

\begin{tabular}{|c|l|}
\hline S.No. & Parameter Name \\
\hline 1 & Research \\
\hline 2 & Training and Placement \\
\hline 3 & Distance Learning \\
\hline 4 & Forums \\
\hline 5 & Library \\
\hline 6 & Pedagogy \\
\hline 7 & Discipline \\
\hline 8 & Presentations \\
\hline 9 & Assignments \\
\hline
\end{tabular}

In table-I the first five are considered as outside class parameters whereas the last four are the inside class parameters. The above parameters have been formulated using the Knowledge of Domain Experts (Expert Knowledge); learning of Knowledge Engineers and Knowledge Acquisition Tool used includes Questionnaire, Books, Magazines, Journals, Reports, Databases, and Internet etc. The fuzzy variables assigned to these group of attributes that will act as an input to the fuzzifier is as shown in table-II

Table-2. Fuzzy Variables For Input Paramters

\begin{tabular}{|l|l|}
\hline Fuzzy Variable & Degree of Membership \\
\hline Null & 0 \\
\hline Very Low & 0.2 \\
\hline Low & 0.4 \\
\hline Medium & 0.6 \\
\hline High & 0.8 \\
\hline Very High & 1.0 \\
\hline
\end{tabular}

Then the decision vector determines the impact of one parameter on another and also the educational institution on the whole. Then the performance of all the attributes is rated on the scale of 0 to 4 . Figure 1 below shows the step by step process for achieving the success of the institution.

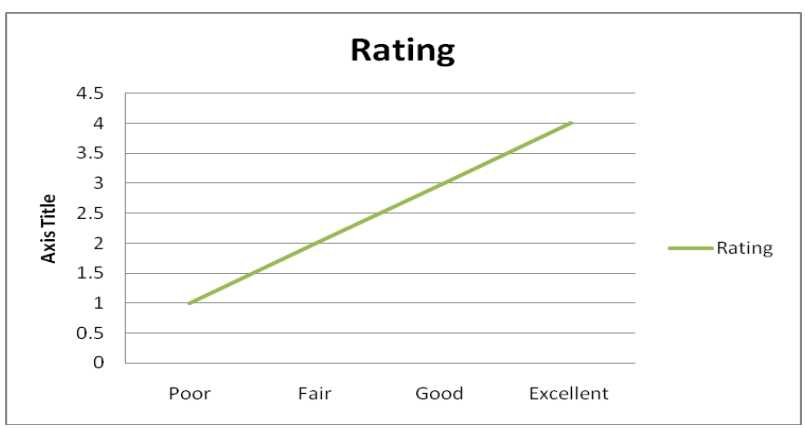

Figure 1: Correlation of rating and performance

\section{TOOLS AND TECHNIQUES}

Learning System basically explains the process involved in calculating the academic performance with the help of the weight age assigned to parameters which further helps in getting the institution at the top ranking by filling up the pitfalls in the structure of the institution. If $\mathrm{W}$ is the weight age assigned to different parameters then parameters can be rated on the scale from 1 to 4 . The permutation and combination of different parameters helps in filling up the pitfalls of an institution. Consider the following:

$f(x)=f(p) U f(q)$

Where $\mathrm{f}(\mathrm{x})=$ Academic performance, $\mathrm{f}(\mathrm{p})=$ Outside class parameters, $\mathrm{f}(\mathrm{q})=$ Inside class parameters.

\subsection{Outside Class Parameters}

$f(p)=f(a, b, c, d, e) ; f(a, b, c, d, e) € f(x)$ 
In this, the function $f(p)$ denotes outside class parameters which is affected by library(a), forums(b), training and placement(c), research(d) and distance learning courses(e). All these parameters have individual affect on the overall academic performance.

\subsection{Inside Class Parameters}

$$
f(q)=f(w, x, y, z) ; f(w, x, y, z) € f(x)
$$

In the above mathematical function, $\mathrm{f}(\mathrm{q})$ indicates inside class parameters which are affected by pedagogical Initiative (w), presentation assessment (x), discipline (y) and assignment based test. These factors too have a vital impact in enhancing the academic performance. To calculate the decision score of any single main attribute with its all sub factors the following summation formula is defined and used:

$$
C i=\sum_{n=1}^{m} P n W n
$$

Where $\mathrm{m}=$ number of sub-factors in the attribute;

$\mathrm{P}=$ Fuzzy value of nth parameter,

$\mathrm{W}=$ Weight of the relative parameter.

For example in case of the library (S.No. 5 in Table-II) we can have the sub factors like reference books, journals, bar coding, capacity, newspapers, reading rooms, centrally managed etc wherein bar-coding and capacity of students has been assigned the lowest weight-age, therefore their permutation and combination has been made with other parameters having lower factor in order to get the one conclusion. The user interface for the same is as shown in Figure2:

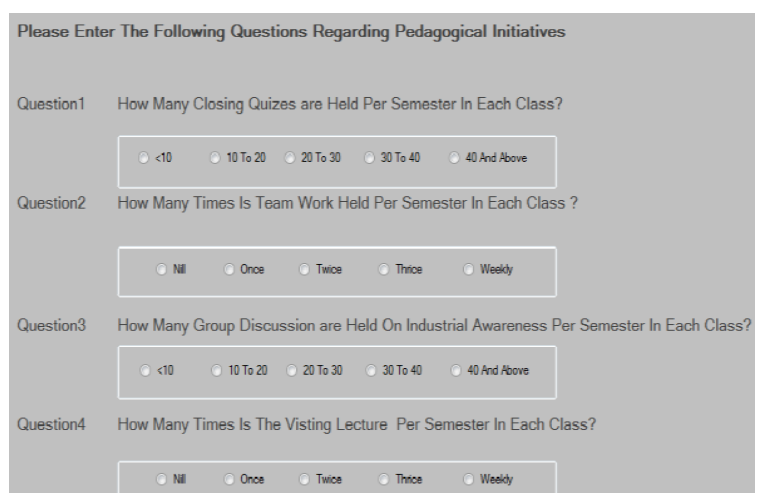

Figure 2(a): Query driven User interface of Level 1 Abstraction of Inside Class Parameters.

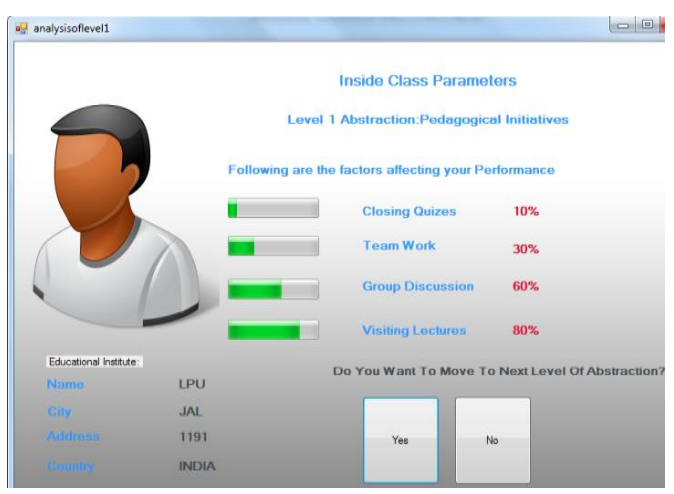

Figure 2(b): Progress Report of Level 1 Abstraction based upon the answers given.
This will help academic institution to know their drawbacks in particular area which will further help in improving the academic performance of the universities. In the same way weightage has been assigned to different parameters and permutation and combination have been deduced in order to get the final result. The output has been obtained after rigorous analysis and re-engineering of the different parameters looking at the dependencies and degree of membership. The fuzzy expert system of academic performance evaluation is shown figure 3 :

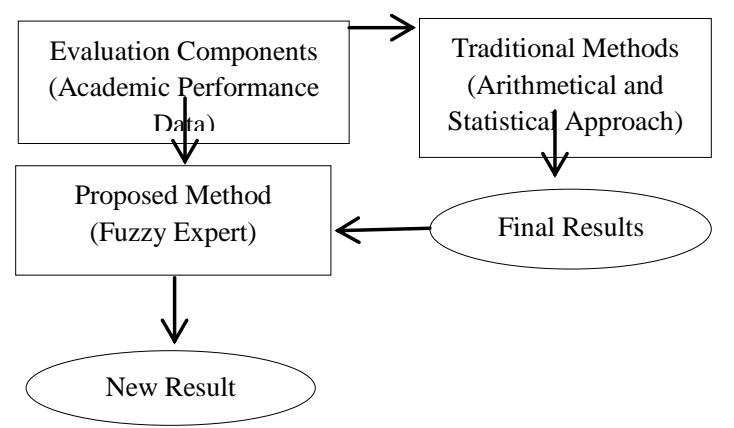

Figure 3: Fuzzy Expert System for Academic performance evaluation

\section{RESEARCH FINDINGS USING FUZZY IN MATLAB}

The research findings of a single parameter (semester-wise) of Teachers Performance Evaluation in Higher Education is determined under pedagogical initiatives taken by a teacher [S.No. 6 in Table-I)

Main Attribute Sub Factors (Max Weight 1.0000)

- Proficiency in teaching (0.0054)

- Personal Interest in Teaching (0.0075)

- $\quad$ Presentation \& Communications skills (0.0063)

- $\quad$ Speaking Style \& Body language (0.0050)

- Content knowledge (0.0059)

- Lecture preparation (0.0067)

- $\quad$ Language Command (0.0059)

- Response to Student queries (0.0067)

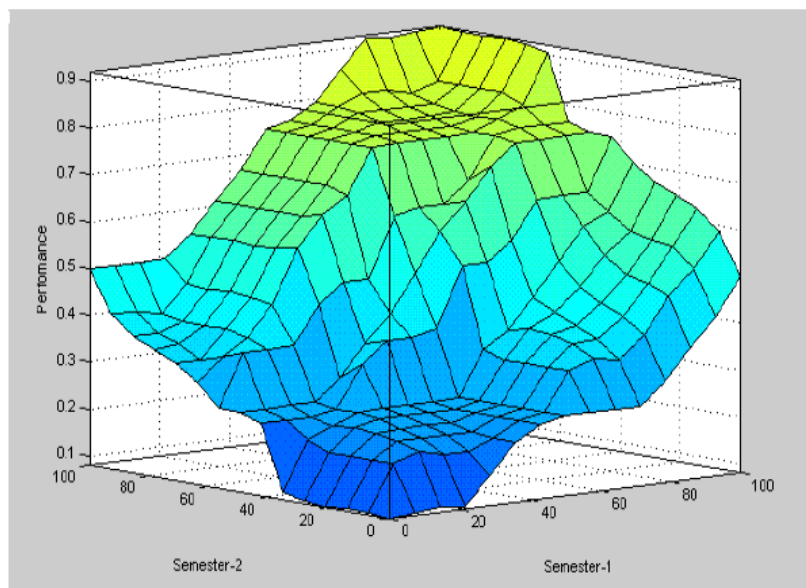

Figure: 4 Surface viewer of Academic Performance Evaluation of Teacher 
Likewise all the inside and outside class parameters are considered, are rated, the average total of inside class parameters is found, then the average total of outside class parameters is found and finally the average of inside and outside class parameters is found to check the overall functioning and rating of an educational institution. Then looking at the inter and intra dependencies in the linguistic variables take, the suggestive improvements are proposed for the betterment of learning in an educational institution.

\section{CONCLUSION AND FUTURE DIRECTION}

In the present work a unique mathematical model has been formulated for academic performance synthesis and analysis of an institute. The model is used for crafting decision through fuzzy logic and decision vectors to deliver the suggestions on improvement of academic performance of the institute. It is proposed to fine tune the model and the decision support mechanism through endurance and more of real time testing. This will lead this to an expert decision support system that will measure the permutations and combinations of impact of one parameter on the other and will also help an educational institute to rate its performance in comparison with the expected performance and average performance till date. Thus this intelligent system will be the one of its kind for academic performance synthesis and evaluation, which can be timely used by the institute for present evaluation and prognosis for betterment.

\section{REFERENCES}

[1] H. Amin, A. R. Khan, Acquiring Knowledge for Evaluation of Teachers 'Performance in Higher Education - using a Questionnaire. International Journal of Computer Science and Information Security (IJCSIS) 2(2009), 180-187.

[2] Daniel Kahneman, P. S. (1982). Judgment under uncertainty Heuristics and biases. New York: Cambridge University Press.

[3] S.Ammar, W.Duncombe, B.Jump, R.Wright, Constructing a fuzzyknowledge-based-system: An application for assessing the financial condition of public schools. Expert Systems with Applications, 27(2004), 349-364.

[4] S.M.Bai, S.M.Chen, A new method for students" learning achievement using fuzzy membership functions. In Proceedings of the 11th Conference on artificial intelligence, Kaohsiung, Taiwan, Republic of China. (2006)

[5] D.Biggs, M.Sagheb-Tehrani, Providing developmental feedback to individuals from different ethnic minority groups using expert systems. Expert Systems, 25(2008), 87-97.

[6] A.Berrais, A knowledge-based expert system for earthquake resistant design of reinforced concrete buildings. Expert Systems with Applications, 28 (2005), 519-530.

[7] S.M.Chen, C.H.Lee, New methods for students evaluating using fuzzy sets. Fuzzy Sets and Systems, 104(1999), 209-218

[8] D.F.Chang, C.M.Sun, Fuzzy assessment of learning performance of junior high school students. In Proceedings of the 1993 first national Symposium on fuzzy theory and applications, Hsinchu, Taiwan, Republic of China, 1993, pp. 1-10.

[9] C. F.Cheung, W.B.Lee, W. M.Wang, K.F.Chu, S.To, A multi-perspective knowledge-based system for customer service management. Expert Systems with Applications, 24(2003), 457-470.

[10] T.T.Chiang, C.M.Lin, Application of fuzzy theory to teaching assessment. In Proceedings of the 1994 second national conference on fuzzy theory and applications, Taipei, Taiwan, Republic of China, 1994, pp. 92-97.

[11] H. K. H.Chow, K.L.Choy, W.B.Lee, F.T.S.Chan, Design of a knowledge-based logistics strategy system. Expert Systems with Applications, 29(2005), 272-290.

[12] J.A.Clark, F.Soliman, A graphical method for assessing knowledge-based systems investments. Logistics Information Management, 12(1999), 63-77.

[13] A.J.Day, A.K.Suri, A knowledge-based system for postgraduate engineering courses. Journal of Computer Assisted Learning, 15(1999), 14-27.

[14] J. Durkin, Application of Expert Systems in the Sciences. OHIO J. SCI. 90 (1990), 171-179.

[15] D.J.Fonseca, G.Uppal, T.J.Greene, A knowledge-based system for conveyor equipment selection. Expert Systems with Applications, 26(2004), 615-623.

[16] M.Hamidullah, Comparisons of the Quality of Higher Educations in Public and Private Sector Institutions, $\mathrm{PhD}$ Thesis, University of Arid Agriculture Rawalpindi, PAK, 2005.

[17] H.Iranmanesh, M.Madadi, An Intelligent System Framework for Generating Activity List of a Project Using WBS Mind map and Semantic Network Proceedings of World Academy of Science, Engineering and Technology. 30 (2008), 338-345.

[18] A.Kazaz, Application of an Expert System on the Fracture Mechanics of Concrete. Artificial Intelligence Review. 19(2003), 177-190.

[19] R.Kumra, R.M.Stein, I.Assersohn, Assessing a knowledgebase approach to commercial loan underwriting. Expert Systems with Applications, 30(2006), 507-518.

[20] S. H. Liao, Problem solving and knowledge inertia. Expert Systems with Applications, 22(2002), 21-31.

[21] J.Ma, D.Zhou, Fuzzy set approach to the assessment of student- centered learning. IEEE Transactions on Education, 43(2000), 237-241.

[22] W.W.Melek, A.Sadeghian, A theoretic framework for intelligent expert systems in medical encounter evaluation. Expert Systems, 26(2009), 87-97.

[23] M.Naeemullah, Designing a Model for Staff Development in Higher Education of Pakistan, $\mathrm{PhD}$ Thesis, University of Arid Agriculture Rawalpindi, PAK, 2005.

[24] T.T.Pham, G.Chen, Some applications of fuzzy logic in rules-based expert systems, Expert System, 19(2002), 208-223. 
[25] J.Pomar,C.Pomar, A knowledge-based decision support system to improve sow farm productivity. Expert Systems with Applications, 29(2005), 33-40.

[26] W. K.Wang, A knowledge-based decision support system for measuring the performance of government real estate investment. Expert Systems with Applications, 29(2005), 901-912.

[27] W. K.Wang, H.C.Huang, M.C.Lai, Design of a knowledgebase performance evaluation system: A case of high-tech state-owned enterprises in an emerging economy. Expert Systems with Applications. doi:10.1016/j.eswa.2007.01.032.

[28] W.Wen, W. K.Wang, T.H.Wang, A hybrid knowledge based decision support system for enterprise mergers and acquisitions. Expert Systems with Applications, 28(2005a), 569-582.

[29] W.Wen, W.K.Wang, C.H.Wang, A knowledge-based intelligent decision support system for national defence budget planning. Expert Systems with Applications, 28(2005b), 55-66.
[30] M.H.Wu, Research on applying fuzzy set theory and item response theory to evaluate learning performance. Master Thesis, Department of Information Management, Chaoyang University of Technology, Wufeng, Taichung County, Taiwan, Republic of China,2003.

[31] M.R.Shen, Y.Y.Tang, Z.T.Zhang, The intelligent assessment system in Web-based distance learning education. 31st Annual Frontiers in Education Conference, 1(2001), TIF-7-TIF-11.

[32] N.H.Yim, S.H.Kim, H.W.Kim, K.Y.Kwahk, Knowledge based decision making on higher level strategic concerns: System dynamics approach. Expert Systems with Applications, 27(2004), 143-158.

[33] L.A. Zadeh, Fuzzy sets. Inform. and control, 8 (1965), 338-353.

[34] L.A.Zadeh, The concept of a linguistic variable and its application to appropriate reasoning. Information sciences, 8(1975), 43-80. 